\title{
Editorial
}

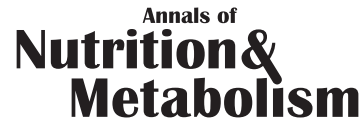

\section{Tenth Annual Hydration for Health Scientific Conference Embodies Excellence and Research Exchange}

A decade! The 10th anniversary of the Hydration for Health Scientific Conference was celebrated in Evian, France on June 26-27, 2018, with an opening day Hydration for Health Academy (first instituted in 2016), followed by a day-long scientific program that included research, clinical, and educational topics.

As one who has participated in the entire 10-year series, I can attest that this conference has greatly advanced our understanding of optimal human hydration and the effects of underhydration, within various demographic/ socioeconomic groups and regions of the world. To illustrate, Table 1 presents selected topics that have been addressed since 2009. These topics were international in scope, as presented by professionals from the following countries and global regions: Australia, Brazil, Canada, China, Europe, France, Indonesia, Mexico, Poland, Sweden, Switzerland, United Kingdom, and United States. Thus, it is obvious to me that this annual conference has stimulated many new research ideas, produced peer-reviewed publications, developed a new generation of young hydration scientists, and encouraged collaborative efforts. The latter has been evident in the alliances formed with other scientific and clinical organizations. For example, the audiences at several conferences heard presentations by leaders of professional societies, including the
European Federation of the Associations of Dietitians (EFAD), European Association for the Study of Obesity, International Society of Nephrology, Ensemble Prévenons l'Obésité Des Enfants (EPODE, Together Let's Prevent Childhood Obesity), and Drink Up! (Partnership for a Healthier America).

\section{The 2018 Conference Program}

In the pages which follow, brief articles describe the presentations that were delivered on June 27, 2018. Because this was the 10th Anniversary Conference, Dr. Erica Perrier, a physiologist affiliated with Danone Research in France, creatively designed her 30-minute talk around the theme of the "top 10" advances in hydration science. Her topics (i.e., including low volume drinkers, copeptin as a component of the neuroendocrine response to defend body water, and new statistical approaches that evaluate the role of vasopressin in chronic diseases) represent key advances during the past decade that originated at, or were encouraged by, this conference.

The next 3 manuscripts in this supplement of Annals of Nutrition and Metabolism focus on children. The first provides a review of water drinking habits and the barriers to

\begin{tabular}{ll}
\hline KARGER & $\begin{array}{l}\text { (C) } 2019 \text { The Author(s) } \\
\text { Published by S. Karger AG, Basel Open }\end{array}$ \\
E-Mail karger@karger.com & $\begin{array}{l}\text { This article is licensed under the Creative Commons Attribution- } \\
\text { NonCommercial-NoDerivatives 4.0 International License (CC BY- } \\
\text { www.karger.com/anm }\end{array}$ \\
$\begin{array}{l}\text { NC-ND) (http://www.karger.com/Services/OpenAccessLicense). } \\
\text { Usage and distribution for commercial purposes as well as any dis- } \\
\text { tribution of modified material requires written permission. }\end{array}$
\end{tabular}


Table 1. Selected topics that were presented at previous Hydration for Health scientific conferences, 2009-2017

Effects of dehydration on brain function and cognitive performance

Cellular processes involved in total body water balance and movement of water between fluid compartments

Relationships between water consumption and renal diseases, including acute kidney injury, chronic kidney disease, kidney stones, urinary tract infections

Epidemiological links between low daily water intake and the following chronic diseases/disorders: diabetes, cardiovascular disease, obesity, metabolic syndrome

Chronic underhydration: habitual low-volume drinkers

Multiple factors that induce and regulate thirst

Self-assessment of daily hydration status: urine color, thirst, body weight change

Hormonal regulation of total body water via arginine vasopressin (AVP), angiotensin, and atrial natriuretic peptide

Hydration needs of pregnant and breastfeeding women

The relationship of daily water intake to weight loss

Teaching children to value healthy drinking habits

Positive parental role models of healthy drinking habits and beverage choices

Encouraging healthy drinking in schools by creating schedules that allow students to drink from fountains and use toilets

Programs that improve community water quality, sanitation, and waterborne illnesses

optimal drinking at school. Dr. Jeanne H. Bottin and colleagues promote water consumption in schools via multiple interventions that combine educational, environmental, and behavioral support for adequate drinking and optimal cognition. Expanding consideration of cognition, Daniel Westfall, Northeastern University, USA, notes that children are an understudied group and that the cognition literature provides inconsistent findings. In an effort to rectify this situation, he reviews the definition of cognition and the domains of which it is composed, explains how cognition has been measured in both field and laboratory studies, presents the results of neuroimaging studies, and describes the relationship between hydration and academic achievement in children. Third, Dr. Schätzer of the Institute for Preventive Cardiology and Nutrition in Austria describes efforts to improve nutrition education, student drinking behavior, and the local school environment (e.g., sugar sweetened beverages offered at vending machines). Due to the existing infrastructure, staff, facilities, and policies, he believes that schools provide a logical site to implement programs and interventions, which promote healthy hydration practices for 10- to 18-year-old pupils.

In the article by Belogianni and colleagues, a joint initiative is described that seeks to increase awareness of healthy hydration practices among dietitians and provide evidence-based resources for patients and clients. Named the European Healthy Hydration Awareness Campaign, this initiative combines the resources of EFAD and Danone Research to generate a webinar, a tutorial, and an online hydration resources center, among other benefits. Examples of these resources can be viewed by entering the term "European Healthy Hydration Awareness Campaign" into your search engine.

On a larger scale, community and international efforts to prevent kidney diseases are described in the 2 articles written by Professor Etienne Macedo, MD, PhD, Department of Medicine, University of California San Diego, USA. With the advent of disease classification systems, our understanding of acute kidney injury (AKI) has evolved. For example, the International Society of $\mathrm{Ne}$ phrology in 2013 launched the 0 by 25 campaign with the goal that no patient should die from preventable or untreated AKI in low-resource areas by 2025. As a result, we now know that community-acquired AKI in low-income and low-middle income countries have common risk factors. A subsequent project, the Global AKI Snapshot study, provided insights into the recognition, treatment, and outcomes of AKI worldwide. In her first article, she comments on the main findings and lessons learned from the 0 by 25 initiative. Second, Professor Macedo describes 
a future study in 3 communities bordering Lake Chapala, Mexico. Before implementing this research, she and her colleagues will determine the water, sanitation, and hygiene characteristics of the target population and evaluate the incidence of diarrheal disease. The goals of this study will be to determine if consumption of unsafe water is associated with an increased incidence of gastroenteritis leading to episodes of AKI and to determine if the provision of clean water to the residents of these communities (i.e., as a research intervention) is associated with a decreased incidence of clinical complications.

The final 2 publications in this special supplement involve the increasing incidence of kidney disorders resulting from the combined effects of strenuous labor in a hot environment, inadequate water intake, and other lifestyle or work environment factors (e.g., nonsteroidal anti-inflammatory drugs, renal infections, diet, pesticides, heavy metals). Dietitian-Researcher Fabiana Nerbass, Nephrology Division, Pró-Rim Foundation, Brazil, examines the feasibility of conducting kidney health research in factories. Chronic kidney disease of unknown etiology was the focus of this pilot study. More than 25 hydration, kidney function, personal, circulatory, blood, and urinary variables were successfully observed. The authors declare industrial research of this type feasible, but also described the limitations of conducting research in a factory environment. In my opinion, such future research studies will have greater external and internal validity if the following features are incorporated into the experimental design: on-site measurements of environmental conditions, chronic changes of kidney function measurements across months and years, recorded histories of previous kidney disease or dysfunction, chest/wrist heart rate monitor values that describe the intensity of the work performed, verification of the extent of dehydration and hyperther- mia in workers, and recording physiological measurements immediately before, during (i.e., lunch break), after the work shift. Dr. Richard Johnson, University of Colorado, USA, also considers industrial scenarios from the perspective of global warming, which may result in kidney disorders, disability, and loss of productivity. His previously published research focused on chronic kidney disease among Central American laborers. Given the increase of air temperatures worldwide, there is a great need to better understand how heat stress can induce kidney disease, how best to provide adequate hydration, and ways to reduce the negative effects of chronic heat exposure in work environments.

Since 2016, attendees have overwhelmingly expressed their enjoyment of the Young Researcher Competition; it generates excitement. Six invited speakers are allowed only 3 minutes each to present their research on stage; the audience then selects, by electronic vote, a winner for the Young Researcher Award. The 2018 recipient was Gabrielle Giersch, USA, for her project titled, "Mild Dehydration by 24 h Fluid Restriction Increases Evening Fatigue and Sleep Duration." Her abstract appears with those of the five other invited contestants on the final pages of this journal supplement.

The breadth of the topics and the interchange of ideas that appear in this special supplement demonstrate that the 2018 conference in Evian, France, was as successful as the 9 previous Hydration for Health Scientific Conferences (Table 1). This event provided a fitting conclusion for the first decade of successful conferences and stimulated interest in future discoveries regarding human hydration.

Lawrence E. Armstrong, PhD, FACSM, Guest Editor Professor Emeritus, University of Connecticut Hydration and Nutrition, LLC, Newport News, VA, USA 